\title{
Investigation of electrode arrangement on ionic wind velocity for hole-type electrostatic precipitator
}

\author{
H. Kawakami ${ }^{1}$, T. Inui ${ }^{1}$, T. Sato ${ }^{2}$, Y. Ehara $^{2}$ \& A. Zukeran ${ }^{3}$ \\ ${ }^{1}$ Fuji Electric Co., Ltd., Japan \\ ${ }^{2}$ Department of Electrical and Electronic Engineering, \\ Tokyo City University, Japan \\ ${ }^{3}$ Department of Electrical and Electronic Engineering, \\ Kanagawa Institute of Technology, Japan
}

\begin{abstract}
Electrostatic precipitators (ESPs) have been extensively used to decontaminate polluted gases exhausted from industrial plants and to clean air in buildings, etc., because of their high collection efficiency. However, the collection of low resistivity particles by the conventional ESPs is known to be difficult. These particles are generated from various sources such as marine engines, diesel automobiles and power generation engines. The low resistivity particles cause particle detachment from a collection plate by an induction charge, i.e., dust reentrainment, resulting in poor collection efficiency. In this study, it was investigated to improve the effect of the ionic wind for the collection efficiency of the hole-type ESP. The experiments were carried out using a needle-to-plate discharge electrode. The plate electrode has a hole, and the ionic wind pass through the hole. PM was guided to the hole for re-entrainment phenomenon control by the ionic wind. Most particles are transported into the hole by pressure difference and ionic wind. As a result, it was founded that the ionic wind passes through into the hole, when the needle electrode was arranged at the centre of the hole. The maximum ionic wind was achieved when the pore size was the same with the gap distance, and the collection efficiency increased with increasing the ionic wind velocity.

Keywords: marine diesel, electrostatic precipitator, diesel particulate matter, re-entrainment, ionic wind.
\end{abstract}




\section{Introduction}

Electrostatic precipitators (ESPs) have been extensively used to decontaminate polluted gases exhausted from industrial plants and to clean air in buildings, etc., because of their high collection efficiency. However, the collection of low resistivity particles by the conventional ESPs is known to be difficult. These particles are generated from various sources such as marine diesel engines, diesel automobiles and power generation engines. The low resistivity particles cause particle detachment from a collection plate by an induction charge, i.e., dust reentrainment, resulting in poor collection efficiency [1].

Several ideas for the conventional ESPs that have been proposed to suppress reentrainment are as follows;

1) Collection electrode coated with a dielectric sheet [2];

2) Mixing water mist with gases [3];

3) Using an ESP as an agglomerator [4, 5];

4) Silent discharge type ESP [6];

5) Application of gradient force [7];

6) ESP by low frequency AC field [8].

However, these concepts achieved only limited success for minimizing the reentrainment under the high dust-loading and high gas temperature condition.

Recently, an electrohydrodynamically-assisted ESP (EHD ESP) for marine diesels was proposed for minimizing reentrainment [9]. EHD ESP utilizes ionic wind to transport the charged particles effectively into the zero electrostatic field zone attached to the collection plate. The hole-type ESP was also suggested to overcome the reentrainment $[10,11]$. The hole-type ESP utilized differential pressure to transport reentrained particles effectively into the low gas velocity space from the high gas velocity space through multiple small holes.

In this study, it was investigated to improve the effect of the ionic wind for the collection efficiency of the hole-type ESP. The experiments were carried out using a needle-to-plate discharge electrode. The plate electrode has a hole, and the ionic wind pass through the hole. The ionic wind velocity was measured by a vane wheel flow sensor. The collection efficiency was calculated by the particle concentration measured using a scanning mobility particle sizer and a particle counter. The ionic wind velocity and the collection efficiency for various arrangements of the needle electrode and the hole-punched plate electrode were investigated.

\section{Experimental setup}

A schematic diagram of the experimental system is shown in Fig. 1. The system consists of a particle generator (PALAS, DNP-3000), a compressor and a needleto-plate discharge electrode. That has also a dilution machine, a scanning mobility particle sizer (SMPS, TSI) and a particle counter (RION, KC-01E) as the measurement system. Carbon particles generated by the aerosol generator, which can generate particles similar to diesel particulate matter, are introduced into the needle-to-plate electrode. A part of the gas is sampled, and then the 
particle concentration was measured by SMPS and the particle counter after dilution.

The configuration of the needle-to-plate discharge electrode is shown in Fig. 2. The electrode has a needle electrode, hole-punched plate electrode and the case. Although a hole type ESP has multiple needles and holes, the experimental electrode consisted of one needle electrode and one hole. The main gas velocities

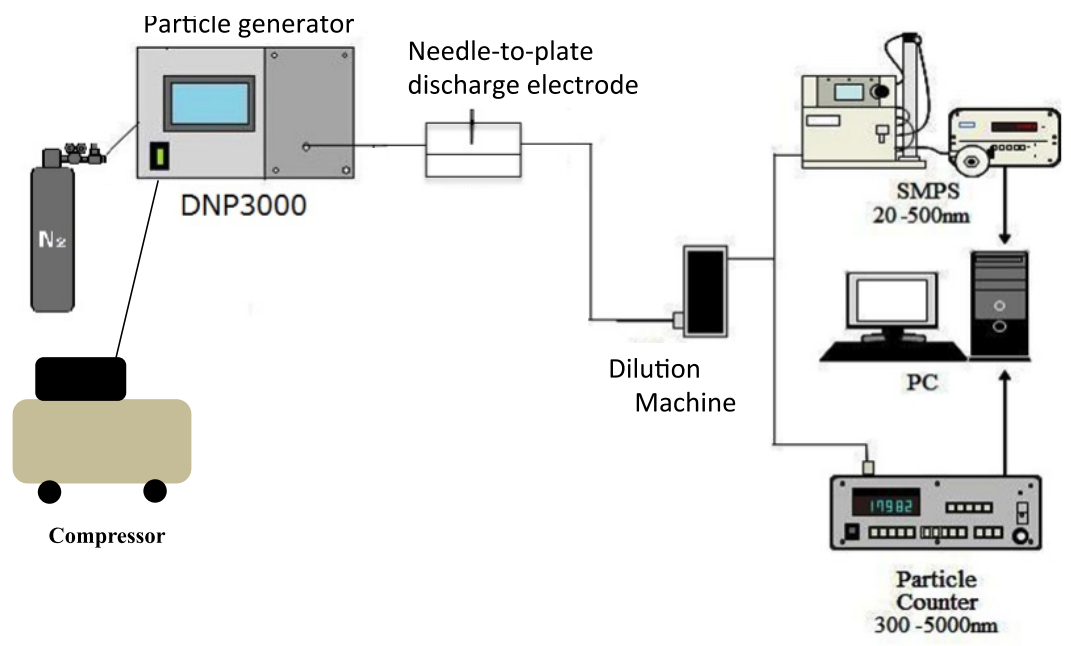

Figure 1: Schematic diagram of the experimental system.

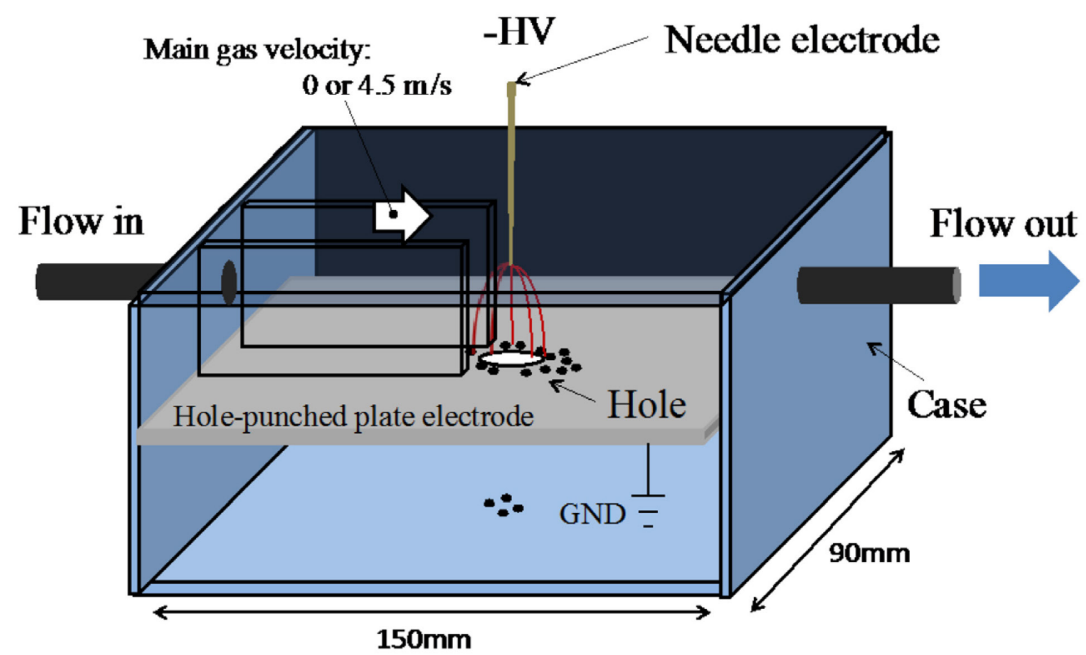

Figure 2: Configuration of needle-to-plate discharge electrode. 
were $4.5 \mathrm{~m} / \mathrm{s}$. A negative high voltage was applied to the needle electrode, and the hole-punched plate electrode and the case were grounded. Particles are charged by ions generated by a corona discharge at the tip of needle electrode. Charged particles migrate forward to the hole on the plate electrode by an electric force and an ionic wind, and then they pass through the hole, i.e. particles are collected.

The detail of the electrodes is shown in Fig. 3. Both of the pore size $\phi$ of hole and the gap distance $\mathrm{d}$ of electrode were between $5 \mathrm{~mm}$ and $30 \mathrm{~mm}$, the location of the needle electrode $\mathrm{X}$, which was the distance from the center of the hole, was between $0 \mathrm{~mm}$ and $10 \mathrm{~mm}$. The ionic wind velocity was measured at under the hole by a vane wheel flow sensor (Hontzsch, ZS16GE), as shown in Fig. 3. Negative DC high voltages between $-4 \mathrm{kV}$ and $-15 \mathrm{kV}$ were applied to the needle electrode. Ionic wind was measured without the aerosol at the gas velocity of $0 \mathrm{~m} / \mathrm{s}$.

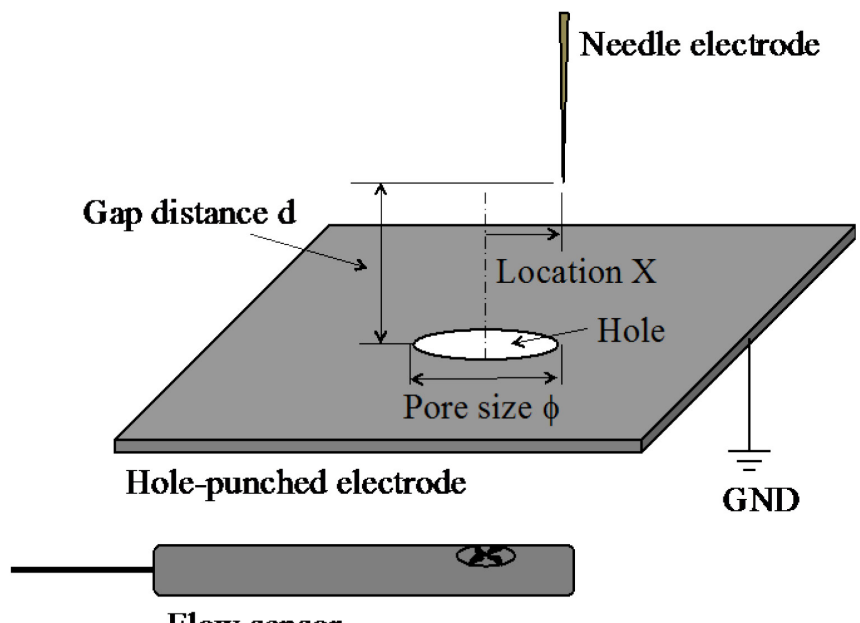

Flow sensor

Figure 3: Detail of the electrode.

\section{Result and discussion}

The arrangement of the needle electrode and the hole was investigated to obtain the high ionic wind velocity. The ionic wind velocity as a function of the discharge current for various locations of needle electrode $\mathrm{X}$ is shown in Fig. 4. The ionic wind was measured without the aerosol at the main gas velocity of $0 \mathrm{~m} / \mathrm{s}$. The distance $\mathrm{d}$ between the tip of needle electrode and the hole-punched plate electrode was $20 \mathrm{~mm}$. The ionic wind velocity at $X$ of $0 \mathrm{~mm}$ increased with increasing the discharge current. The velocities at $X$ between $5 \mathrm{~mm}$ and $10 \mathrm{~mm}$ were almost 0 at the current until $15 \mu \mathrm{A}$ or $20 \mu \mathrm{A}$, and they decreased with the increases in the location $\mathrm{X}$. The ionic wind passed through the hole at $\mathrm{X}$ of $0 \mathrm{~mm}$ as shown in Fig. 5, however the plate electrode was an obstacle for the ionic 
wind at the location $X$ larger than $5 \mathrm{~mm}$. This figure showed that a high velocity ionic wind is obtained, when the needle electrode is arranged at the center of the hole.

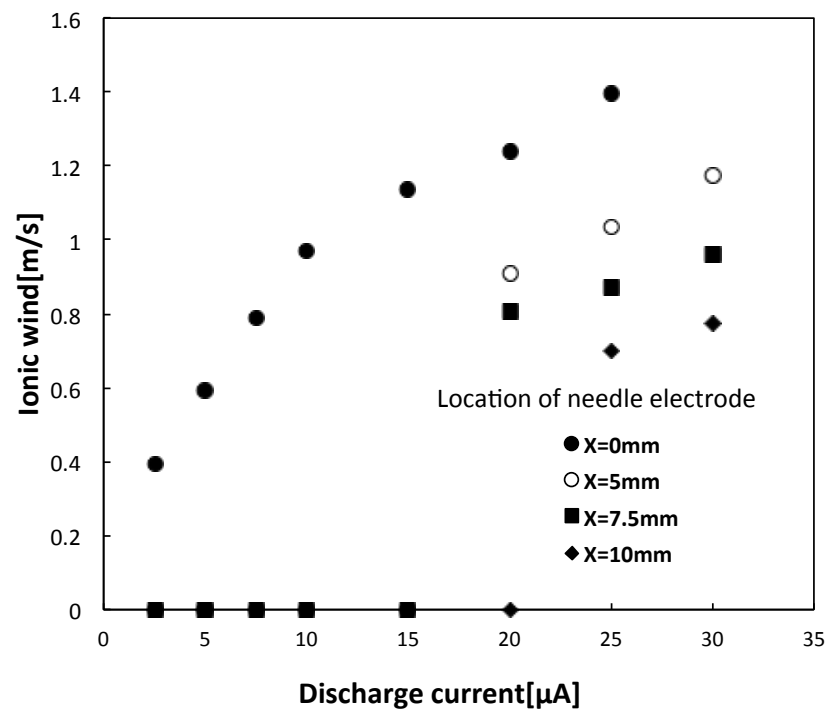

Figure 4: The ionic wind velocity as a function of the discharge current for various locations of needle electrode $\mathrm{X}$.

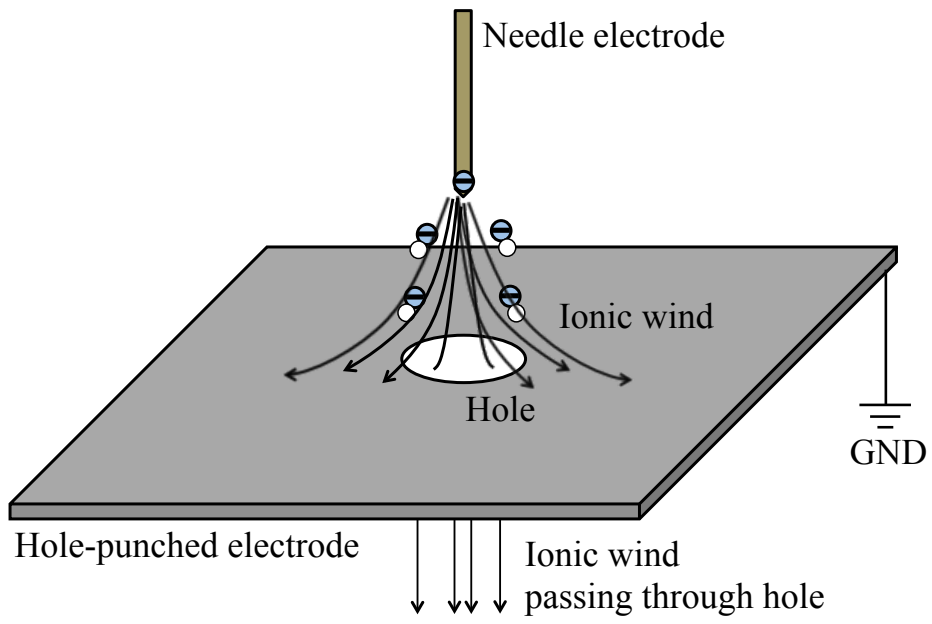

Figure 5: Model of ionic wind passing through the hole. 
It was investigated the ionic wind as a function of the current for various distances $d$ between the tip of needle and the hole-punched plate electrode. This result at the pore sizes of $10 \mathrm{~mm}$ and $20 \mathrm{~mm}$ are shown in Figs 6 and 7. The needle was arranged at the center of the hole, when $\mathrm{X}$ is 0 . The ionic wind velocity increased as the current increased at all distances, so that the ionic wind was depended on the number of space charges. The velocity was the fastest at the distance d of $10 \mathrm{~mm}$ at the pore size of $10 \mathrm{~mm}$ as shown in Fig. 6, and of $20 \mathrm{~mm}$ at that of $20 \mathrm{~mm}$ as shown in Fig. 7.

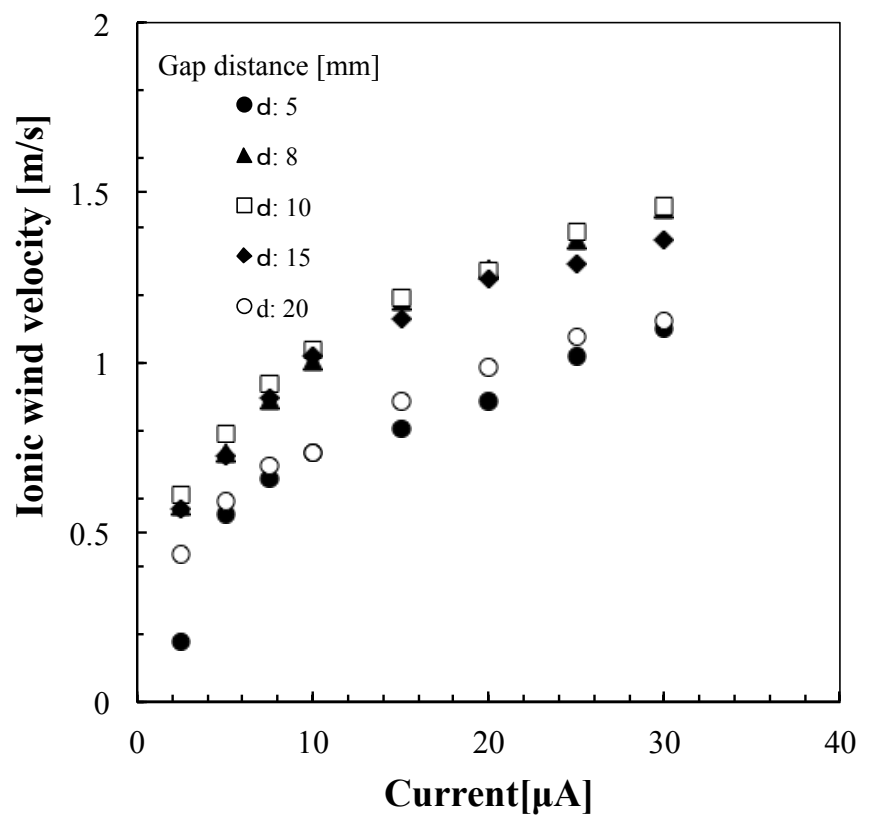

Figure 6: The ionic wind velocity as a function of current for various distances d. (The pore size $\phi: 10 \mathrm{~mm}$. The location X: $0 \mathrm{~mm}$.)

Accordingly, the ionic wind as a function of the rate $(\phi / \mathrm{d})$ at the pore sizes of $10 \mathrm{~mm}$ and $20 \mathrm{~mm}$ are shown in Figs 8 and 9. The ionic winds had the maximum value at the rate of approximately 1 both pore sizes. Therefore, it is found that high ionic wind velocity is obtained, when the pore size $\phi$ is the same with the gap distance $\mathrm{d}$.

The collection efficiency as a function of particle diameter for various pore sizes at the gap distance of $20 \mathrm{~mm}$ was measured using the SMPS and the particle counter to investigate the effect of the electrode arrangement. The collection efficiency was measured with the aerosol at the main gas velocity of $4.5 \mathrm{~m} / \mathrm{s}$. The particle size distribution (the pore size $\phi: 20 \mathrm{~mm}$, the gap distance d: $20 \mathrm{~mm}$, the location $\mathrm{X}: 0 \mathrm{~mm}$ ) is shown in Fig. 10. The distributions were 


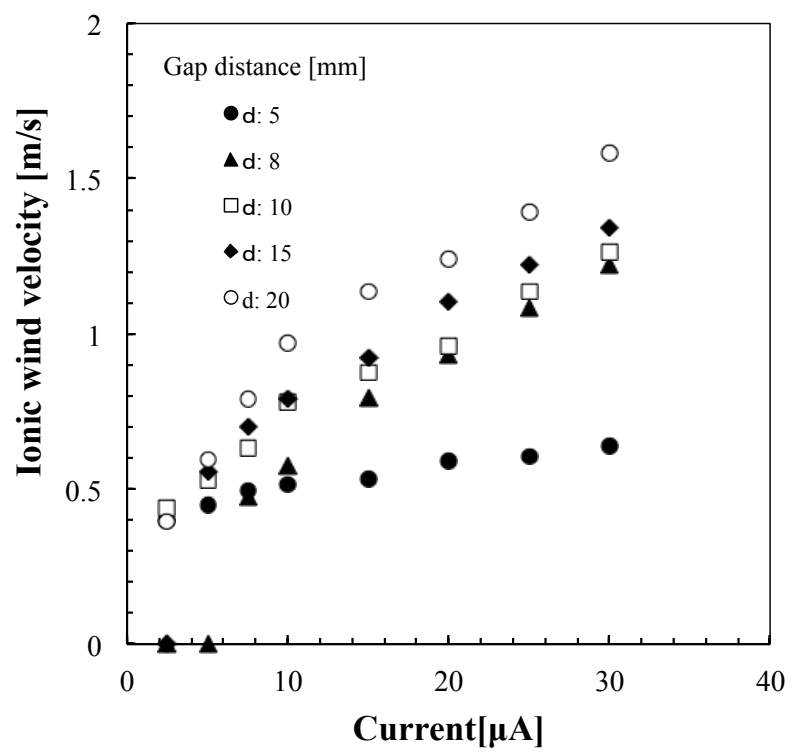

Figure 7: The ionic wind velocity as a function of current for various distances $\mathrm{d}$. (The pore size $\phi: 20 \mathrm{~mm}$. The location X: $0 \mathrm{~mm}$.)

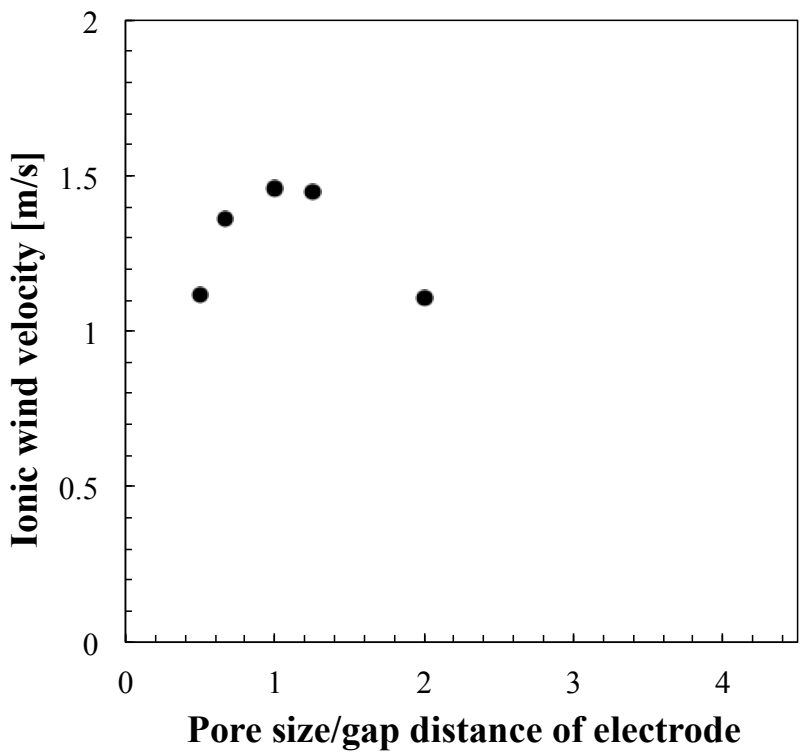

Figure 8: The ionic wind velocity as a function of rate $(\phi / d)$ at the pore sizes of $10 \mathrm{~mm}$. 


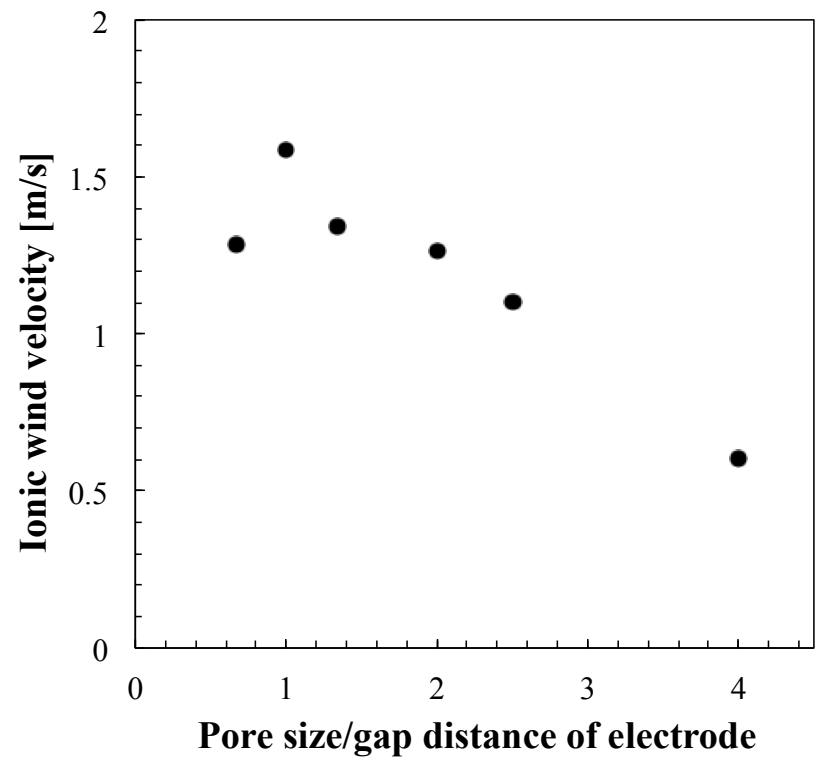

Figure 9: The ionic wind velocity as a function of rate $(\phi / \mathrm{d})$ at the pore sizes of $20 \mathrm{~mm}$.

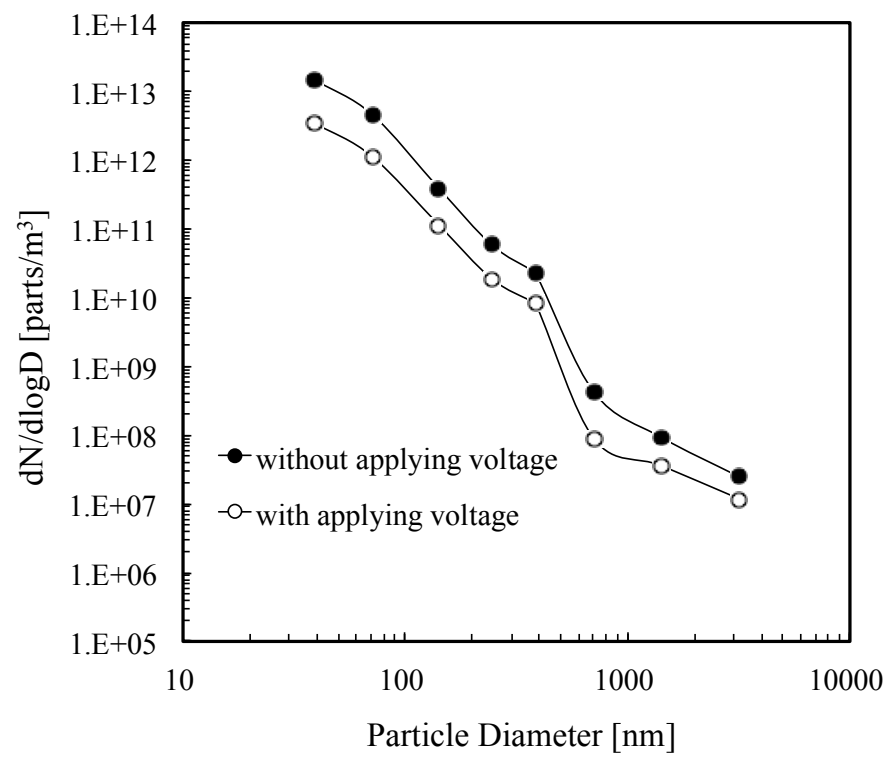

Figure 10: Particle size distribution. 
measured on the downstream side of the needle-to-plate electrode. The distribution without applying voltage to the needle-to-plate electrode had the maximum fraction at the particle size of $30 \mathrm{~nm}$. The distribution with applying voltage was lower than that without applying voltage due to the effect of the electrostatic precipitation. The particle size-dependent collection efficiency for various pore sizes is shown in Fig. 11. The collection efficiency $\eta$ was calculated by equation (1);

$$
\eta=\left(1-\frac{N_{o n}}{N_{o f f}}\right) \times 100
$$

where, $N_{\text {off }}$ is the particle concentration without applying high voltage to the needle-to-plate electrode, $N_{\text {on }}$ is that with applying high voltage.

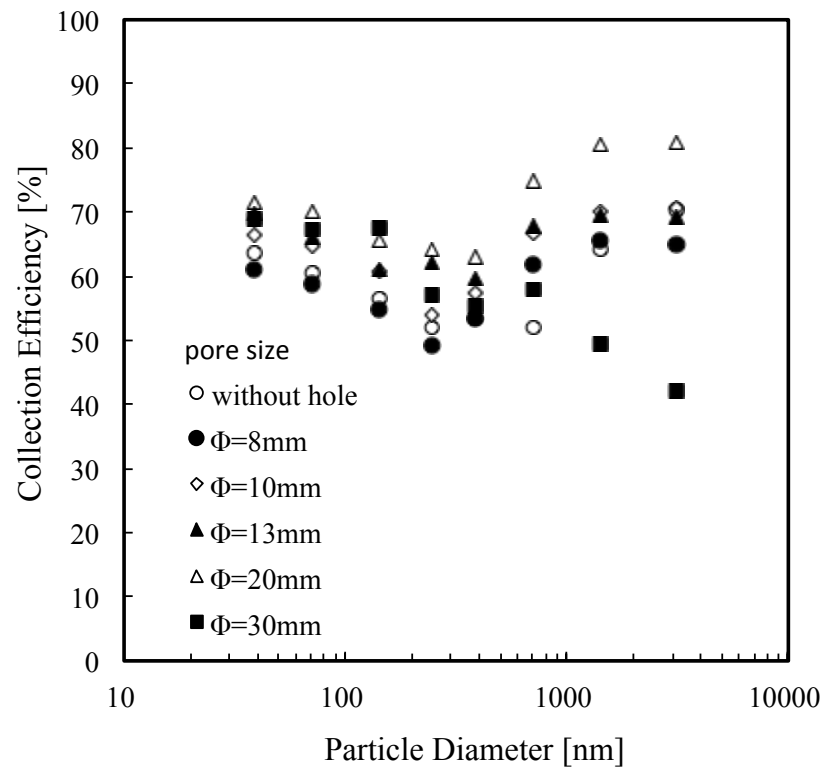

Figure 11: Particle size-dependent collection efficiency for various pore sizes at the gap distance of $20 \mathrm{~mm}$.

The minimum efficiency was occurred between 100 and $1000 \mathrm{~nm}$. This was attributed to the Cunningham factor, which migration velocity of charged particles smaller than $1000 \mathrm{~nm}$ increase. The efficiency increased with increasing the pore size from 8 and $20 \mathrm{~mm}$. The efficiency of $20 \mathrm{~mm}$ was greater than that of $30 \mathrm{~mm}$ due to the effect of the ion wind. This result indicates that the collection efficiency is improved when the pore size is the same with the gap distance. 


\section{Conclusion}

In this study, it was investigated that the collection efficiency was improved using an ionic wind in the hole-type ESP. The ionic wind velocity and the collection efficiency for various electrode arrangements were measured. Results are follows;

1) The ionic wind passes through into the hole on the plate electrode, when the needle electrode is arranged at the centre of the hole on the plate electrode.

2) The ionic wind velocity increases with increasing the discharge current.

3) The maximum ionic wind and high collection efficiency are achieved when the pore size is the same with the gap distance.

\section{References}

[1] A. Zukeran, Y. Ikeda, Y. Ehara, M. Matsuyama, T. Ito, T. Takahashi, H. Kawakami, and T. Takamatsu: "Two-Stage Type Electrostatic Precipitator Re-entrainment Phenomena under Diesel Flue Gases”, IEEE Trans. Ind. Applicat., Vol. 35, No. 2, pp. 346-351, 1999.

[2] T. Takahashi, Y. Kawada, A. Zukeran, Y. Ehara, T. Ito, "Inhibitory Effect of coating electrode with Dielectric Sheets on Re-entrainment in Electrostatic Precipitator", Journal of Aerosol Science, Vol. 29, Suppl. 1, pp. 485-486, 1998.

[3] A. Zukeran, W. Jindai, Y. Kawada, Y. Ehara, T. Ito, T. Takahashi, H. Kawakami, T. Takamatsu, "Effect of surfactant on re-entrainment phenomena in an electrostatic precipitator", Trans. IEE of Japan, Vol. 119-A, No. 3, pp. 267-272, 1999.

[4] F. Isahaya, "Development on electrostatic pre-coagulator combined with after-cyclone dust collector", Hitachi Hyoron, Vol. 49, Vol. 11, pp. 77-80, 1967.

[5] S. Masuda, J. D. Moon, K. Aoi, “AUT - AINER Precipitator System - an Effective Control Means for Diesel Engine Particulates", Actas 5, Congreso Int aire Pure, 1980 Tomo 2, pp. 1149-1153, 1982.

[6] Y. Kawada, T. Kubo, Y. Ehara, T. Takahashi, T. Ito, A. Zukeran, T. Takamatsu, "State of the collecting particles on electrodes in electrostatic precipitator with barrier discharge", Trans. IEIE of Japan, Vol. 121-A, No. 6, pp. 516-521, 2001.

[7] B.-J. Sung, A. Aly, S.-H. Lee, K. Takashima, S. Katsura, A. Mizuno, "Fine Particles Collection Using an Electrostatic Precipitator Equipped with an Electrostatic Flocking Filter as the Collecting Electrode", Plasma Process. Polym., Vol. 3, pp. 661-667, 2006.

[8] K. Yasumoto, A. Zukeran, Y. Takagi, Y. Ehara, T. Takahashi, T. Ito, "Suppression of Particle Deposition onto Downstream Wall in an AC Electrostatic Precipitator with Neutralization", International Journal of Environment and Waste Management, Vol. 2, Nos. 4/5, pp. 399-411, 2008. 
[9] T. Yamamoto, T. Mimura, N. Otsuka, Y. Ito, Y. Ehara, A. Zukeran, "Diesel PM Collection for Marine and Automobile Emissions Using EHD Electrostatic Precipitators“, IEEE Trans. Ind. Appl., Vol. 46, No. 4, pp. 1606-1612, 2010.

[10] H. Kawakami, A. Zukeran, K. Yasumoto, T. Inui, Y. Ehara, T. Yamamoto, "Diesel PM Collection for Marine Emissions Using Double Cylinder Type Electrostatic Precipitator", International Journal of Plasma Environmental Science \& Technology, Vol. 5, No. 2, pp. 174-178, 2011.

[11] H. Kawakami, A. Zukeran, K. Yasumoto, T. Inui, Y. Enami, Y. Ehara, T. Yamamoto, "Numerical Simulation of Three-Dimensional Particle Migration and Electrohydrodynamics of Double Cylinder Electrostatic Precipitator", International Journal of Plasma Environmental Science \& Technology, Vol. 6, No. 2, pp. 104-110, 2012. 